\title{
Ofcom acts and consults on silent calls
}

\section{Manana Shrimpling}

Journal of Direct, Data and Digital Marketing Practice (2014) 16, 133-135. doi:10.1057/dddmp.2014.68

Who: Ofcom

Where: London

When: 1 October 2014

Law as stated at: 8 October 2010

\section{Penalty followed notification}

\section{Review followed penalty}

Last revised in 2010

\section{Abandoned and silent calls}

\section{What happened}

Ofcom has imposed a penalty of $£ 10,000$ on specialist insurer Ageas Retail Limited (Ageas) for persistent misuse of an electronic telecommunications network. Ageas was found to have made multiple abandoned calls from its call centres. Ofcom had issued a notification to Ageas in April 2014 stating that it had reasonable grounds for believing that Ageas had carried out such activity as part of its own-initiative investigation. Ageas was given an opportunity to make representations and to take steps for securing that the misuse was brought to an end and not repeated.

The penalty was in the end imposed by Ofcom, taking into account factors such as the steps that Ageas had taken since being notified of the misuse, as well as steps Ageas had committed to put in place, and Ofcom's own statement of policy on the persistent misuse of an electronic communications network or service. The $£ 10,000$ penalty has to be paid within 30 days. On the same day as it issued a public notification of the penalty, Ofcom announced a review of how it uses its persistent misuse powers, focusing on silent and abandoned calls.

\section{Review of Ofcom's powers}

Ofcom has powers under the Communications Act 2003 relating to 'persistent misuse of networks or services' and must publish a statement of its general policy on the exercising of such powers. The policy was last revised in 2010 and includes examples of activities that Ofcom considers as falling within such 'misuse', including silent and abandoned calls.

An 'abandoned call' is where the person making the call terminates it after the consumer has picked up the receiver. 'Silent calls' are a type of abandoned call where the consumer answers a call but can hear nothing and has no means of establishing whether anyone is at the end of the line. Both of these can occur when, for example, an organization uses automatic 


\section{Mitigation measures demanded}

\section{Stakeholder input}

Current users of ACS

\section{Report and proposals} in 2015 calling systems (ACS) and all call centre agents are busy when the call recipient answers the phone.

The current policy sets out the types of measures organizations using ACS may take to help avoid making abandoned or silent calls and to limit the consumer harm caused as a result of such calls. These measures include:

- letting the phone ring for a minimum of 15 seconds before the call is terminated;

- playing a brief recorded message in the event of an abandoned call, no later than 2 seconds after the phone has been picked up or after the consumer begins to speak. The message should, as a minimum, identify the company on whose behalf the call was made, provide a free or basic/ geographic rate number the consumer can call to decline further calls and should not be used to market goods or services. (Initially, Ofcom took the view that Ageas had also fallen foul of this latter requirement by including a marketing message in its recorded message, but after considering Ageas's representations and reviewing the message content, Ofcom changed its mind.);

- provide a caller ID so the consumer can return the call if they wish. Any call so made should not be used as a marketing opportunity without the consumer's consent;

- guarantee the presence of a live call centre agent if a further call is made within 72 hours of a consumer receiving an abandoned call, or within 24 hours in cases where equipment used by the call centre has identified an answering machine;

- limit the number of abandoned calls made to no more than 3 per cent of live calls per campaign or per call centre over a 24 -hour period.

Ofcom has sought input from stakeholders on issues such as the main types of harm experienced by consumers from nuisance calls, what the key drivers are for silent and abandoned calls, and views on potential changes to Ofcom's policy to help reduce harm (including, for example, specifying the types of processes Ofcom looks for organizations to have in place).

\section{Why this matters}

ACS are used by many types of organizations, including telemarketing companies, market research companies, debt collection agencies, charities carrying out fundraising activities and companies wishing to contact existing customers. Their heaviest users in recent times have been marketers of payment protection insurance mis-selling claims services.

The recent fine for Ageas is a reminder for organizations using the technology to review their processes alongside Ofcom's policy to determine whether they have appropriate measures in place to avoid making abandoned or silent calls and to limit consumer harm caused by such calls. Responses to Ofcom's call for inputs were to be provided by 7 November 
2014. Ofcom then plans to publish a consultation in Q1 of 2015 setting out any proposals for changes to its policy and a final statement in early Q3.

Manana Shrimpling, solicitor, Osborne Clarke, Bristol

\section{Big data and data protection paper from ICO}

\section{Sue Gold}

Journal of Direct, Data and Digital Marketing Practice (2014) 16, 135-137. doi:10.1057/dddmp.2014.69

Who: Information Commissioner

Where: United Kingdom

When: 27 July 2014

Law stated as at: 7 August 2014

Different privacy risks

\section{Setting the scope}

Focus on transparency

Definitions

\section{What happened}

The Information Commissioner's Office (ICO) published a 50-page paper on 27 July entitled 'Big data and data protection'. The paper gives an overview of the privacy issues that arise from using big data and suggests how to comply with the Data Protection Act 1998. The ICO states that the paper's aim is to ensure that the different privacy risks of big data are considered alongside its benefits. It emphasizes that the 'benefits cannot simply be traded with privacy rights'.

The paper invited comments by 12 September 2014 and asked for feedback on three specific questions:

- whether the paper reflects all the relevant issues;

- whether the ICO should produce further guidance documents and, if so, what they should cover; and

- whether there are any other practical measures and tools needed to address the issues in addition to those already contained in the paper.

The paper focuses in particular on the importance of transparency. It emphasizes that, where big data involves personal data, then data protection laws still apply and should not be seen as a barrier to progress, but as a stimulus to 'develop innovative approaches to informing and engaging with the public'.

\section{ICO conclusions on big data}

The ICO references the Gartner definition of big data, although it emphasizes that there is no fixed meaning. Big data is defined, the paper says, by volume, variety and velocity (the three Vs). Big data typically 